\title{
Las huellas de Nicolás Maquiavelo en los Ensayos de Michel de Montaigne*
}

\author{
Niccolò Machivelli's traces in Michel Montaigne's Essays
}

Eugenia Mattei**

\section{RESUMEN}

En este artículo se trata, en términos generales, de evidenciar los

Palabras puntos de contacto entre Michel Montaigne y Nicolás Maquiavelo. En este sentido, se busca realizar un aporte a la recepción de Maquiavelo en la obra de Montaigne para iluminar, de modo simultaneo, el pensamiento político de Montaigne. En una primera parte se realiza una síntesis biográfica de los autores y se sistematiza los tres tipos de abordajes acerca de la relación entre Maquiavelo y Montaigne en la literatura especializada. Se analizan en segundo término las referencias explícitas a Maquiavelo, que dan cuenta que Montaigne efectivamente leyó al autor italiano. En tercer lugar, se muestran los motivos maquiavelianos en los escritos de Montaigne respecto de cómo se desenvuelve la política en el palacio y lo que generalmente tiene que hacer un hombre si se quiere dedicar a la política. Por último, se presentan las conclusiones del trabajo realizado.

\section{SUMMARY}

In general terms, this article highlights the points of contact between Michel Montaigne and Niccolo Machiavelli. In this sense, we seek to contribute to the reception of Machiavelli in Montaigne's work to illuminate, simultaneously, Montaigne's political thought. In the first part, a biographical synthesis of the authors is made, and three types of approaches to the relationship between Machiavelli and Montaigne in the specialized

Keywords: politics, Machiavellian, skepticism, ethics.

* Cabe destacar que utilizamos la edición de Losada para el caso de Montaigne y la de Colihue y de Alianza para el caso de Maquiavelo. Sin embargo, se cotejó con las traducciones en el idioma original para ambos autores. En el caso de Maquiavelo se modificaron algunas traducciones para esclarecer algunos puntos oscuros utilizando la edición italiana al cuidado de Mario Martelli.

** Argentina. CONICET-UBA. eugeniamattei@gmail.com 
literature are systematized. Secondly, we analyze the explicit references to Machiavelli, which show that Montaigne did indeed read the Italian author. Thirdly, the Machiavellian motifs in Montaigne's writings are shown concerning how politics unfolds in the palace and what a man generally has to do if he wants to engage in politics. Finally, the conclusions of the work carried out are presented. 


\section{I. ¿Vidas paralelas? A modo de introducción ${ }^{1}$}

Nicolás Maquiavelo (1469-1527) huye de cualquier clasificación: fue un político, pero también un pensador que teorizó sobre diversos asuntos. Como menciona Quentin Skinner, Maquiavelo puede ser ubicado como un pensador transicional, porque habitó entre un viejo mundo que no terminaba de morir y uno nuevo que no terminaba de nacer. Escribió sus textos más significativos en el desierto político, como son El príncipe y los Discursos sobre la primera década de Tito Livio (Buasi 159-218), pero también fue un actor que participó en las decisiones del palacio. Fue jefe de la Segunda Cancillería y secretario de los Diez de Libertad y de Paz, la comisión de la República de Florencia que se ocupaba de los problemas militares y de la política exterior. A través de ese cargo, Maquiavelo pudo adquirir conocimientos sobre asuntos militares y, más aún, tener un protagonismo en la conducción de la guerra contra Pisa (1496-1509). Maquiavelo siempre interrogó de modo apasionado sobre la guerra, pero no solo en un sentido teórico, sino incluso como tarea. De hecho, buscó crear una milicia que otorgara a Florencia una fuerza militar propia y, para ello, logró obtener el apoyo del confaloniero Piero Soderini. Un desafío político que implicó dos grandes tareas: tuvo que enfrentar, por un lado, el obstáculo de los optimates a armar al pueblo y, por otro lado, interesar al pueblo a incorporarse a la milicia. En diciembre de 1506 se creó una nueva magistratura, Los nueve oficiales de las Ordenanzas y de la milicia florentina, de la cual Maquiavelo fue su primer secretario ${ }^{2}$. Su vida fue una vida de guerras, atravesada en gran parte por los conflictos bélicos entre Francia y España sobre el sur y el norte de la península durante

1 Utilizamos el clásico título de la obra de Plutarco (2009) como el comienzo de nuestro texto por dos razones. Primero, Maquiavelo (2000) realiza, de algún modo, el ejercicio de Plutarco al comparar distintas biografías a través de un hilo (como la dupla Aníbal y Escipión en los Discursos sobre la primera década de Tito Livio) y, a su vez, Plutarco era el autor favorito de Montaigne (especialmente Ensayo de los Libros, II. 10). Segundo, y lo más importante, el mismo ejercicio que propone Plutarco al poner biografías conectadas por algún sentido, es el que intentamos hacer aquí para el dúo Maquiavelo-Montaigne, señalando sincronías y puntos de contactos entre ambos.

2 Maquiavelo fue nombrado secretario de la magistratura de los Diez de la Guerra, creada en 1384, en julio de 1498. Frente a experiencia acumulada por las constantes derrotas que vivieron los florentinos en la guerra contra Pisa, debido en gran parte al protagonismo de las tropas mercenarias, en 1506 Maquiavelo organizó una milicia de infantería y en 1507 se le fue asignado el cargo de secretario de Los Nueve. El logro más eminente de este hecho fue que, en 1509, Florencia reconquistó Pisa.

La ordenanza de 1506 que estableció la milicia florentina fue suprimida en 1512. 
treinta años (Fournel, Zancarini). Todo ese conflicto logró tener una resolución con la batalla de Pavía, en febrero de 1525, que significó un gran fracaso militar de Francia a favor de España. Muy cerca del fallecimiento de Maquiavelo, en 1527, el saqueo de Roma por parte de las tropas alemanas y españolas terminó por consagrar la victoria imperial en mayo del mismo año.

En un sentido diverso, Michel de Montaigne (1533-1592) también escapa a cualquier estereotipo. Hay un Montaigne psicólogo, pero también etnógrafo e historiador. Como Maquiavelo, Montaigne hacía convivir su pasión por las letras con el ejercicio de la política. Fue conseiller en el tribunal de Burdeos, de 1557 a 1570, y dos veces alcalde de la misma ciudad entre 1581 y 1585 . Luego de una decena de años de actividad política, convulsionada por las guerras religiosas, vendió su puesto de magistrado y se retiró a su castillo heredado por la muerte de su padre para seguir leyendo a los clásicos. Este retiro de los asuntos públicos le permitió dedicarse a la administración de sus propiedades y a la escritura de los Ensayos ${ }^{3}$. Cuando viajó a Italia, en 1580, le anunciaron que lo habían elegido alcalde, evento que marcó su vuelta a la política.

Montaigne provenía de una familia noble reciente; su padre, Pierre Eyquem, era un caballero gascón cuyos antepasados eran comerciantes del vino y propietarios de tierras cercanas a Burdeos, y su madre, Antoinette de Loupes, una figura menos presente en los Ensayos, era de origen español y se cree que también judío (Burke). Por el contrario, Maquiavelo provenía de una familia antigua del popolo, de Florencia del siglo XII. Según el Libro di ricordi (2007), los recursos del padre de Maquiavelo eran más bien modestos. Sus ingresos económicos procedían de sus propiedades en Sant'Andrea en Percussina, que en su mayoría consistían en contratos de agricultores arrendatarios.

Los motivos por los cuales Maquiavelo abandonó la política obedecieron más a factores de tipo externo. Al regresar los Médici al poder en Florencia, el 7 de noviembre de 1512, Maquiavelo fue despojado de

3 Durante su vida Montaigne público dos ediciones de Los Ensayos: la de los libros I y II en 1580, y la de los libros I, II y III, con agregados en los primeros dos libros, en 1588. Posteriormente, hizo agregaciones a los márgenes de libro hasta su muerte en 1592. Marie de Gournay publicaría la edición de 1595, que comprende adiciones y que difiere muy poco del texto de 1588 . 
su cargo en la Cancillería y llevado a la cárcel el 13 de febrero de 1513, acusado de participar en un complot, hasta el 12 de marzo (gracias a una amnistía brindada por el Papa León X). Posteriormente se vio obligado al exilio político en su casa de campo en Sant 'Andrea en Percussina. Y ahí, en el conocido Albergaccio, es donde escribió sus obras más difundidas, como fueron El príncipe y los Discursos sobre la primera década de Tito Livio (Bausi, Viroli, Vivanti). En el caso de Montaigne, podríamos decir que su una decisión fue más mentada. En aquella época se podían vender los cargos y esto fue lo que hizo Montaigne con su puesto de magistrado en 1570 para irse a su castillo también heredado por la muerte de su padre. Se recluyó en la torre, su refugio en una época convulsionada por guerras religiosas, para seguir leyendo a los clásicos. Es más, replegarse al mundo privado era un plan que hacían varios de sus contemporáneos como es el caso de Michel L'Hôpital, canciller de Francia. La lectura, en definitiva, se muestra como un refugio cuando el mundo se vuelve demasiado hostil.

En el caso particular de Montaigne, habitar el mundo privado no era una opción de segundo orden. En muchas partes de los Ensayos lo celebra por ser el lugar en donde reinan el ocio y la libertad: "Me conformo con gozar del mundo, sin ocuparme de él, y vivir una vida solo perdonable y que no pese ni a mí ni a los demás" (2011 854). De hecho, en su biblioteca había una inscripción, con fecha de 1571, en la que decía que ahí se consagran la libertad, la tranquilidad y el ocio. Como mencionamos más arriba, Montaigne se retira de los asuntos públicos en 1570 y hasta 1580 se dedica a administrar sus propiedades y trabajar en los Ensayos; Maquiavelo se retiró de los asuntos del palacio al mundo privado con la llegada de los Médici al poder en Florencia, el 7 de noviembre de 1512. Al respecto, puede indicarse la famosa carta de Maquiavelo a su amigo, Francesco Vettori, el 10 de diciembre de 1513, en la cual se muestra el vínculo que mantiene el florentino con los autores clásicos en su ostracismo político (Maquiavelo 2013 134139). Cuando obtuvo la autorización, retornó a Florencia para nunca más volver a ser funcionario (Bausi, Vivanti, Viroli).

Tanto para Maquiavelo como para Montaigne, la lectura y la escritura operaron como refugio frente a un mundo atravesado por guerras. En sus trayectorias personales y en cada una de sus obras, escritas de modo sinuoso y con un estilo indirecto, habitan elementos diversos y 
contrapuestos. En este sentido, que Montaigne y Maquiavelo son muy diferentes es algo evidente: El príncipe de Maquiavelo y los Ensayos de Montaigne poseen una naturaleza diversa. Más allá del debate si Maquiavelo tenía alguna esperanza de adquirir un cargo con su obra ante los nuevos señores de Florencia, concordamos con Lefort que "ninguna consideración de orden práctico permite dar cuenta de su intención de escritor" (2010 151). Cuando Maquiavelo emprendió la escritura de El príncipe, en su exilio político, ya tenía cuarenta y cuatros años y poseía una amplia experiencia que le había otorgado insumos para la reflexión política. Y también se había dedicado al registro literario, como la Primera Decenal de 1506. La escritura de Montaigne en los Ensayos tiene su propia singularidad. No fue un escrito dedicado a un político ni tampoco tuvo un tema específico, como puede pasar con el texto de Maquiavelo. Como señala Philipe Desan, en los Ensayos se muestra un pensamiento amorfo y multifacético. A diferencia de Descartes y su preocupación por el contenido, Montaigne, por el contrario, indagó sobre las formas del pensamiento, del conocimiento y de la forma que pueden ser conocidas las cosas a través de otros mundos posibles. La originalidad de los Ensayos fue, según Dessan, ofrecer juicios basados en su experiencia, y opiniones que expresan solo verdades pasajeras y temporales.

Cada uno, a su propia manera y singularidad, realizó una determinada alquimia con todos esos elementos. A partir de esta reconstrucción, que evidencia que Montaigne leyó a Maquiavelo, lo que buscamos es poder sistematizar tres tipos de abordajes acerca de la relación entre Maquiavelo y Montaigne en la literatura especializada.

Primero, se encuentran los autores que afirman que Montaigne fue fuertemente influido por los escritos de Maquiavelo (Sanders, Schaeffer, Borghi, Nicolai). El clásico trabajo de Sylvia G. Sanders muestra a Montaigne como un discípulo de Maquiavelo, especialmente en torno a los problemas morales, la voluntad del príncipe como fundamento del Derecho y una misma racionalidad al comprender los problemas políticos. En el caso de otro clásico texto de la literatura especializada, como es el de Alexander Nicolai, se muestra un minucioso análisis para ilustrar con más radicalidad la influencia de Maquiavelo en Montaigne. Nicolai analiza con atención el ensayo Lo útil y lo honesto, y señala la seducción que Montaigne mantuvo con las ideas de Ma- 
quiavelo. Asimismo, el estudio de Giuliano Borghi aborda lo trágico como una matriz común en el modo de mirar el mundo de Maquiavelo y Montaigne. En las palabras de Borghi, para Montaigne la existencia es trágica porque:

el azar y la suerte no hacen posible la predicción, ya que los eventos escapan a toda norma posible, por eso la existencia es más la cualidad de la excepción que la de la normalidad [se, dunque, caso e fortuna non rendono possibile la previsione giacché gli accadimenti sfuggono a ogni norma possibile, già per questo l'esistenza più la qualita dell'eccezione, che quella de la normalita] (70).

En la misma vereda se encuentra Maquiavelo, quien reconoce en el hombre una continua aporía: sabe de sus propias limitaciones, pero a la vez tiene la necesidad de reafirmar su voluntad para poder compensar esas limitaciones con creatividad.

Segundos se hallan aquellos que ponen a Montaigne como contrafigura de Maquiavelo (Shklar, Grady 2002, 2006, Villey). En el caso de Judith Shklar, se observa una tajante contraposición entre Montaigne y Maquiavelo en torno al uso de la crueldad. Para Shklar, la separación que hace Maquiavelo entre moral y política resulta intolerable para Montaigne. Por más que Montaigne reconoció que había muchas cosas moralmente malas que se hacían en política, jamás las llamó correctas y, según Shklar, Montaigne no podía aceptar como inevitables esas crueldades. $\mathrm{O}$, para decirlo en las propias palabras de la propia Shklar:

En resumen, Montaigne no pensó que estos argumentos amorales (los de Maquiavelo) fueran concluyentes (...) Si los príncipes deben cometer atrocidades, dejen al menos que puedan arrepentirse y que hagan un esfuerzo para evitar ir a la guerra para complacer algún capricho personal, concluyó Montaigne [In short, Montaigne did not think these amoral arguments conclusive (...) If princes must commit atrocities, let them at least regret it and let them make some effort to avoid going to war in order to indulge some personal whim, Montaigne concluded] (25).

Dentro de este grupo de especialistas, tajantes en marcar la diferencia entre Maquiavelo y Montaigne, se destacan los recientes estudios de Hugh Grady que posicionan a Montaigne como el teórico renacentista 
de la resistencia. La complejidad de Montaigne reside en las múltiples perspectivas que habitan en su obra, característica que, según Grady, también comparte con William Shakespeare. En relación con Maquiavelo, los Ensayos de Montaigne dan cuenta de una subjetividad no fijada y disputan con la comprensión que tiene el propio Maquiavelo de una subjetividad que es efecto del poder impersonal del príncipe ${ }^{4}$.

Por último, existen interpretaciones que muestran tanto las afinidades como las diferencias entre ambos autores (Rodríguez Rial, Zaharia, Burke, Whitfield). En el clásico estudio biográfico que realiza Edmud Burke, Montaigne es emparentando con Maquiavelo en tres aspectos: primero, es calificado como un antiutopista, especialmente en lo relativo a la política; segundo, sabía de los poderes impredecibles que podía tener la diosa Fortuna al igual que el propio Maquiavelo; y, por último, era muy consciente de que los príncipes debían utilizar medios malos para obtener un buen fin. Sin embargo, para Burke, Montaigne se aleja de Maquiavelo en la existencia de "leyes generales y universales" para la política. En su reciente artículo, Gabriela Rodríguez Rial ubica a Maquiavelo y a Montaigne en un mismo linaje:

Tanto para Guicciardini como para Maquiavelo y Montaigne, el miedo a la pérdida es compartido por quienes componen los cuerpos políticos, independientemente del régimen político y del grupo o sector social al que pertenezcan. En los Discursos I.11 Maquiavelo reconoce que la religión se asocia con un miedo específico y, con Montaigne, al carácter sugestivo o imaginativo de los miedos que se originan en la falta o exceso de confianza de los hombres en sí mismos Pero el escritor francés es el único de los tres que tematiza el terror pánico (127).

Hecha la reconstrucción de la literatura especializada, es necesario destacar que en este artículo se parte del tercer modo de abordaje para

$4 \quad \mathrm{Al}$ respecto Grady argumenta lo siguiente: "Similarly, of course, Montaigne has long been discussed as a possible source for a number of Shakespeare's ideas, with a similar lack of consensus, much of the problem revolving around the difficulty of identifying any unequivocal verbal echoes of Montaigne by Shakespeare until The Tempest. Here I will be assuming that such influences traveled discursively and need not have been direct to be meaningful. With that assumed, I will argue that Shakespeare's plays indeed display a multivalent reaction to both Montaignean and Machiavellian themes. In particular, Shakespeare's plays go beyond the logic of The Prince to critique certain of its premises and to explore the cultural crisis of meaning that its logic creates" (120-121) 
dar cuenta de un punto de contacto entre Maquiavelo y Montaigne, pero sin desmerecer las diferencias. En este sentido, se buscará analizar las huellas de Maquiavelo en los Ensayos de Montaigne, es decir, las marcas que dejó su lectura de Maquiavelo. Esto se realizará en torno a dos ejes: primero, las referencias explícitas de Maquiavelo que dan cuenta que Montaigne efectivamente leyó al autor italiano. Aquí analizaremos dos ensayos de Montaigne: "De la presunción" y “Observaciones de Julio César sobre el modo de hacer la guerra". Las obras citadas de Maquiavelo son El príncipe y los Discursos sobre la primera década de Tito Livio. Segundo, veremos la presencia de Maquiavelo en los escritos de Montaigne, pero en un registro más sutil. Para decirlo en otras palabras, indagaremos cómo se desenvuelve la política en el palacio y lo que tiene que hacer un hombre si se quiere dedicar a la política, para echar luz en la relación que existe entre Montaigne y Maquiavelo en torno a estos tópicos. Para ello, indagaremos los siguientes ensayos de Montaigne: "Sobre lo honesto y lo útil", "De la vanidad", "Si el jefe de una plaza asediada debe salir a parlamentar", "De administrar la voluntad" y "El peligroso momento de parlamentar". Análogamente, se evocará de Maquiavelo principalmente El príncipe y algunas referencias a los Discursos sobre la primera década de Tito Livio. En relación con la hipótesis de lectura presente de este artículo, se trata, en términos generales, de evidenciar los puntos de contacto entre Montaigne y Maquiavelo. En este sentido, en este artículo se busca realizar un aporte para la recepción de Maquiavelo en la obra de Montaigne, de modo de demostrar cómo la figura del primero ayuda iluminar el pensamiento político en Montaigne.

\section{Montaigne cita a Maquiavelo}

En sus Ensayos, Montaigne nombra en dos oportunidades de modo explícito a Maquiavelo. Éste aparece en De la presunción (II.17) y en Observaciones de Julio César sobre el modo de hacer la guerra (II.34). Ambas referencias son bastante sinuosas y no muy exhaustivas, pero, como veremos, dan cuenta de que tenía un conocimiento de su obra y también de todo el debate antimaquiavélico de la época.

En De la presunción Montaigne rehúye a cualquier definición de sí mismo. Dice que sabe sostener "una opinión, pero no elegirla". Casi seguidamente dice que prefiere "la duda y la libertad de elegir" hasta que 
la ocasión lo obligue (597). En esa situación de indefinición, admite que se abandona "a la merced de la fortuna". Seguidamente, afirma que prefiere dejarse llevar por la multitud, porque no confía en su capacidad de poder guiar. Prefiere, en este sentido, seguir los pasos señalados por otros que estén más seguros de sus opiniones. Pero luego, rápidamente, admite que las opiniones de esos a quienes prefiere seguir también pueden cambiar. Para decirlo en otras palabras, le resulta fácil cambiar de opinión porque nota que su propia debilidad (es decir, que sus opiniones estén siempre sujetas bajo un fundamento resbaladizo) también se encuentra en las opiniones contrarias. Montaigne es así: tiene una escritura con muchos pliegues y cualquier afirmación es seguida por su negativa.

Esta caracterización de su persona, lejos de ser una disposición individual, es parte de la condición humana y marca el modo en el cual los hombres hacen política. Para Montaigne, la política es un "campo abierto al movimiento y la contestación":

Los discursos de Maquiavelo, por ejemplo, eran bastante sólidos para el tema ${ }^{5}$, y sin embargo ha habido gran facilidad para combatirlos; y los que lo han hecho no hay ofrecido menos facilidad para combatir los suyos [étaient assez solides pour le sujet; si, y a-t-il eu grand'aisance à les combattre, et ceux qui l'ont fait, n'ont pas laissé moins de facilité à combattre les leurs]. Siempre se encontrarán, para su argumento cualquiera, el medio de proveer réplicas, contrarréplicas, dúplicas, tríplicas, y esa infinita maraña de debates que nuestras chicanas alargan en tanto pueden favorecer proce$\operatorname{sos}(598)$.

Los discursos de Maquiavelo, entonces, son sólidos. Pero también encuentran sus réplicas y éstas sus propias réplicas. $\mathrm{O}$, para decirlo de otra manera, si a la afirmación de Maquiavelo puede oponerse la postura antimaquiaveliana, a esta última también puede ponerse una afirmación que la contradiga. Es decir, nada puede sostenerse con certeza y, en gran parte, es por estos desplazamientos que puede verse en Montaigne un escéptico. En este sentido, tanto Sanders como Zaharia señalan que resulta llamativo el tono de esta referencia a Maquiavelo.

$5 \quad$ Es, decir los asuntos políticos. 
Montaigne parece tomar una actitud neutral frente a un autor que era reconocido en aquella época, como luego popularizará Leo Strauss, por ser el maestro del mal. En 1576, el hugonote Innocent Gentillet, en su texto Anti-machiavel, condenaba a Maquiavelo por ser una exaltador de las crueldades en política. Como bien señala Claude Lefort, El príncipe termina siendo el marco teórico de la política Catalina de Médicis, supuestamente plasmada en la masacre de la noche de San Bartolomé, en agosto de 1572. Por eso, llama mucho la atención que Montaigne, en este mismo ensayo, se dedique a hablar de los "deberes de un príncipe", y no se indigne cuando el príncipe rompe su palabra dada:

Aquellos que en nuestros tiempos han considerado en la definición de los deberes de un príncipe el solo bien de los asuntos y lo prefieren por sobre el cuidado de su palabra y conciencia, aprobarían a un príncipe a quien la fortuna hubiera arreglado los asuntos de tal modo que pudiera asegurarlos por una sola vez de faltar a su palabra [Ceux qui, de natte temps, ont considéré, en l'établissement du devoir d'un prince, le bien de ses affaires seulement, et l'ont préféré au soin de sa foi et conscience, diraient quelque chose à un rince de qui la fortune aurait rangé à tel point les affaires que pour tout jamais il les pût établir par un seul manquement et faute à sa parole]. Pero las cosas no son así. Siempre se recae en actitudes semejantes, pues en la vida se firma más de una paz, más de un tratado. El beneficio que los lleva a la primera deslealtad se presenta casi siempre como todas las demás maldades: los sacrilegios, los crímenes, las rebeliones, las traiciones, se emprenden por alguna clase de provecho, pero esa primera ganancia aporta infinitos daños posteriores, arrojando a ese príncipe fuera de toda sociedad y medio de negociación a causa del precedente de aquella infidelidad (592-593).

En Observaciones de Julio César sobre el modo de hacer la guerra, en la referencia II.34, Maquiavelo se encuentra en el mismo párrafo que las menciones a Alejandro, Homero, Escipión, Jenofonte, Marco Bruto, Polibio, Carlos V y Felipe de Comines. En ese contexto se da cuenta de la popularidad de ciertos libros sobre líderes militares, Montaigne afirma que:

en estos tiempos se dice que Maquiavelo aún tiene prestigio en otras partes, pero el finado mariscal Strozzi, que por su parte había 
adoptado a César, sin dudas eligió mucho mejor; pues en verdad este debería ser el breviario de todo hombre de guerra como verdadero y soberano patrono del arte militar [et dit-on de ce temps, que Machiavel est encore ailleurs en crédit; mais le feu maréchal Strozzi, qui avait pris César pour sa part, avait sans doute bien mieux choisi] (663-644).

Esta referencia a Maquiavelo resulta muy sugerente porque muestra la ambivalencia que genera su figura. Por un parte, Montaigne señala que muchos generales se apoyaron en conocimientos tomados de libros y menciona que hay gente que lee a Maquiavelo, pero dice que harían mejor en leer a César como hacía Piero Strozzi (1510-1558), primo de la reina Catalina de Médici y gran militar al servicio de Francia. De esta manera, está rechazando a Maquiavelo en favor de César como autor ${ }^{6}$.

Sin embargo, también hay algo que se dice al pasar, pero que es muy sintomático: "se dice que Maquiavelo aún tiene prestigio en otras partes"; o sea, no en Francia, donde se suscribe al antimaquiavelismo. Si bien esto último haría pensar que Montaigne comparte ese lugar común, porque reproduce el "se dice...," y también pone que es mejor leer a César, al menos en estos temas militares, hay que recordar la cita del otro ensayo en la cual afirma que Maquiavelo tenía sólidos argumentos y que la crítica antimaquiaveliana también le parecía pasible de ser criticada. En algún punto, siguiendo esos pliegues de Montaigne, se puede llegar a afirmar que hasta el mismo Cesar puede ser criticado. Es decir, el rechazo de Maquiavelo en favor de César tampoco es definitivo.

¿Cómo debemos entender esto entonces? En principio, estas referencias parecen demostrar dos cosas: primero, Montaigne observa cosas positivas en Maquiavelo (es sólido en temas políticos); segundo, también observa cuestiones razonables en las críticas a Maquiavelo y que es mejor leer a César sobre asuntos militares. En definitiva, Montaigne afirma y reniega de Maquiavelo, y en ese juego se revela lo que me parece propio de Montaigne: no ser maquiaveliano o antimaquiaveliano, sino escéptico. En este sentido, es bastante significativo el

6 En la cronología de Acantilado figura que Montaigne leyó a César en 1578. Estimamos que se hace referencia a Comentarios sobre la guerra de las Galias. 
hecho de que, cuando menciona la cuestión Maquiavelo-Antimaquiavelo, no lo hace para tomar partido por uno de esos bandos. Lo usa de ejemplo para señalar que a cualquier discurso político se le puede oponer otro igual de convincente, y esto es lo mismo sobre las opiniones en general.

Ahora que hemos restituido y sistematizado las evidencias que dan cuenta de que Montaigne leyó a Maquiavelo, resta dirigirnos a las huellas que dejaron esas lecturas en la textualidad de los Ensayos en torno al tópico de la relación entre moral y política. La elección de este tema se debe a que, en los años posteriores a la publicación póstuma de las obras de Maquiavelo, El Príncipe comienza a ser leído a partir de la recepción de su obra en el espacio intelectual eclesiástico, en el cual se construye la imagen de un Maquiavelo "diabólico", incentivador de la violencia y la crueldad, y, sobre todo, enemigo del cristianismo. Paralelamente, a través del dominico Lancellotto Politi y del poeta Girolamo Muzio, esta construcción de Maquiavelo "como maestro del mal" llega a Italia y El príncipe termina siendo incorporado en el índice de los libros prohibidos por la Iglesia. En el marco de la contrarreforma y las guerras de religión, esta fama de Maquiavelo se propaga por todo el continente europeo, encabezada por jesuitas y hugonotes, y da lugar al conocido antimaquiavelismo. Análagomente, Maquiavelo queda identificado como el teórico de la moral y la política, que pronto da origen a la conocida idea de maquiavelismo y de la razón de Estado (Bausi, 2015, Torres, 2013). Este clásico interrogante irresuelto sobre la relación entre política y moral (que tiene sus derivas sobre la responsabilidad política para quienes sean políticos) puede encontrarse en algunos ensayos de Montaigne.

Asimismo, es necesario destacar que, al decir "huellas", nos valemos del aporte de Carlo Ginzburg en su clásico libro El hilo y las huellas. Lo verdadero, lo falso, lo ficticio. En él, Ginzburg se refiere a las "huellas" que dejó Teseo al caminar por el laberinto y que sirven como metáfora para dar cuenta respecto de cómo se superponen varias textualidades.

\section{Las huellas de Maquiavelo}

Como venimos argumentando a lo largo de este artículo, Montaigne se caracteriza por una escritura sinuosa, con pliegues y matices. En el comienzo de "Sobre lo honesto y lo útil", su autor dice que "nuestra 
modalidad", tanto pública como privada, está repleta de imperfecciones (11). Es decir, "nuestro ser" está hecho por "cualidades enfermizas", como los celos, la envidia o la superstición. Incluso afirma que el hombre también puede ser apoderado por el vicio de la crueldad, por el placer de ver sufrir a otro, y hasta los niños pueden tenerlo. Esos vicios son como semillas:

Quien quitara las semillas de estas cualidades en el hombre, destruiría las condiciones fundamentales de nuestra vida. De ningún modo, hay en toda organización política tareas necesarias que son no solo abyectas sino también viciosas: los vicios encuentran lugar y empleo en la construcción de los lazos sociales, como los venenos en la conservación de la salud (...). El bien público exige que se traicione, se mienta, se asesine: dejemos estos encargos a gentes más obedientes y flexibles (712).

En este párrafo, Montaigne parece recuperar el capítulo XVII de El príncipe: "De la crueldad y la piedad; y si es mejor ser amado que temido o por el contrario mejor temido que amado". Este capítulo es conocido por la descripción que Maquiavelo realiza de la magnética figura de César Borgia. Maquiavelo afirma que éste era cruel, pero más piadoso que el pueblo florentino que, para eludir la fama de cruel, permitió que se destruyera Pistoia. En este sentido, no habría que preocuparse por la "infamia de cruel" si con ello se tiene a los súbditos unidos y leales. De hecho, en el capítulo VII "De los principados nuevos que se adquieren con las armas y la fortuna de otros", Maquiavelo se centra en el modo audaz e inteligente de Borgia en relación con Ramiro d'Orco, su ministro que gobernaba Cesena. Al percibir en el pueblo un odio furibundo por la crueldad [crudeltà] desmedida con que había actuado d'Orco, Borgia hizo colgar al ministro en la plaza de Cesena. La ferocidad de ese espectáculo [ferocità del quale spettaculo] dejó a los hombres del pueblo "satisfechos y estupefactos" [satisfatti e stupi$d i$. Este suceso repone, por un lado, el odio que el pueblo puede sentir por un poder que ejerce la crueldad y, por otro, cómo un líder (Borgia) no puede actuar aisladamente, sino que su acción está ligada a la necesidad de satisfacer al pueblo. El pueblo se encuentra "satisfecho" por librarse de un gobernante cruel y, al mismo tiempo, "estupefacto", es decir, asombrado por la acción de Borgia. Este "spettaculo" feroz y visible para todos produce un efecto: trasmutar las pasiones que tenía 
el pueblo. Para decirlo con nuestras propias palabras, de la oscuridad también puede salir la luz, porque a veces es necesario hacer el mal para evitar un mal mayor.

Siguiendo los rastros más sutiles de Maquiavelo, en otros ensayos de Montaigne encontramos una alusión muy evidente. En una época que repudiaba a Maquiavelo, Montaigne parece parafrasearlo:

Cuando una circunstancia urgente o algún accidente impetuoso e inopinado por necesidad de su posición lo obliga a faltar a su palabra y su fe o lo arroja de alguna manera fuera de su ordinario deber, el príncipe debe atribuir esta necesidad a un golpe de la vara divina: no se trata de vicio, pues ha abandonado su razón por una razón más universal y poderosa, pero ciertamente es una desgracia (720).

Hay una moralidad de la coyuntura, es decir, lo bueno o lo malo se van definiendo según el horizonte histórico en el cual se actúa. Maquiavelo hace un análisis de la administración económica de la crueldad y, en gran parte, Montaigne parece haber entendido esa aritmética de la política. En este sentido, no coincidimos con Judith Sklar, quien sostiene, como ya mencionamos, que, a grandes rasgos, Maquiavelo es el maestro de la crueldad. Esa afirmación opaca los ambigüedades y sutilezas que habitan en el registro maquiaveliano.

En el capítulo XVIII de El príncipe, Maquiavelo advierte que el hombre, como un péndulo, deambula entre el saber engañar cuando sea necesario y ser temerario cuando determinadas situaciones lo exijan. Desde la conocida alegoría zoomórfica del feroz león y el zorro astuto presente ${ }^{7}$, se observa cómo en Maquiavelo opera, de manera constante, lo visible y lo invisible, es decir, la combinación entre fiereza y virtud:

[Pero] es necesario saber colorear bien esta naturaleza, y ser un gran simulador y disimulador [simulatore e dissimulatore]: y es que son tan ingenuos los hombres, y hasta tal punto obran según las ne-

7 Hacemos referencia a la conocida metáfora: "Por lo tanto, dado que un príncipe necesita saber usa bien la bestia, de ellas debe elegir al zorro y al león, porque el león no se defiende de las trampas y el zorro no se defiende de los lobos. Por eso se precisa ser zorro para conocer las trampas y león para estampar los lobos. Los que apoyan simplemente sobre el león no pueden entender este tema" (Maquiavelo 2021 93). 
cesidades presentes, que quien engaña encontrará siempre quien se deje engañar [ingannare] (Maquiavelo 2012 90)

Esta moralidad se vincula con el dilema que sufre cualquier hombre que quiere dedicarse a la política. En este sentido, Montaigne afirma que "hay príncipes que no aceptan a los hombres a medias y desprecian los servicios limitados y condicionados" (715). Por eso, la disyuntiva a la que se enfrentan las personas que quieren dedicarse a la política siempre es: ser fiel a sí mismo o dar cuenta de una ética. Esta disyuntiva a veces no tiene resolución, tiene que ver con una alquimia. Montaigne se define en este ensayo como un "Negociador tierno y novicio y por eso fallar a su propia misión" (712). Esto lo conduce a decidir replegarse a "la forma más privada" de vida (715).

Siguiendo las pistas de este tono maquiaveliano en la escritura de Montaigne, nos dirigimos al ensayo "De la vanidad". Ahí aconseja que

...aquel que va en la multitud debe esquivar, apretar los codos, retroceder o avanzar, incluso abandonar el camino recto según lo encuentre; que viva no tanto según el mismo sino según los demás, no según lo que se propone sino según lo que le proponen; según el tiempo, los hombres, los negocios. Dice Platón que quien sale de los asuntos públicos con los calzones limpios es por milagro (890).

Montaigne parece ser más weberiano que nunca al reconocer que la política implica un "pacto con el diablo" (Weber 168), y continúa sugiriendo que los príncipes demasiado escrupulosos debieran abdicar o retirarse de la vida política en lugar de ser la causa de la ruina de su país.

Hay otros ensayos en los que Montaigne habla del engaño, tópico que obsesionaba a Maquiavelo. Por ejemplo, en el ensayo "Si el jefe de una Plaza asediada debe salir a parlamentar" (1.5), Montaigne aconseja a los príncipes desconfiar de las promesas y, para ello, comienza con la referencia al conflicto entre Lucio Marco y Perseo: el primero realizó los preparativos de un acuerdo y Perseo dio una tregua de varios días. Grave error: tiempo necesario para que el enemigo se armara y pudiera derrotarlo. Montaigne utiliza la mencionada metáfora zoomórfica celebre del capítulo XVIII de El príncipe: "donde no alcanza una piel de león, hay que coser un retazo de piel de zorro, de modo que con esta 
práctica se aprovechan las menores ocasiones de sorpresa" (Montaigne 58).

A pesar de admitir que él mismo se entrega con facilidad a la palabra del otro, Montaigne se muestra muy maquiaveliano al reconocer que, en momentos de guerra, el engaño es necesario y útil. Ya Maquiavelo había destacado en la figura de Ciro su capacidad para el engaño, haciendo de este talento el propulsor de la constitución de su propio reino ${ }^{8}$.

En el ensayo siguiente, "El peligroso momento de parlamentar" (1.6), Montaigne dice que siempre "ha sido un asunto de riesgo confiar a la buena voluntad de un ejército victorioso la observancia de la palabra dada a una ciudad que acaba de rendirse" (59), como ocurrió en la ciudad de Casilino. Y si quedaba algún tipo de dudas de la huella de Maquiavelo sobre los Ensayos, Montaigne dice que no está escrito en ningún lado que no hay que valerse de la estupidez y la cobardía de los enemigos. Una vez más esto parece remitirnos a la enseñanza de Maquiavelo, principalmente en el capítulo XVIII de El príncipe y en el capítulo 19 del primer libro de los Discursos sobre la primera década de Tito Livio: el buen líder debe saber alquimizar al zorro con el león, la astucia con la fuerza, su humanidad con su propia bestialidad.

En el ensayo "De administrar la voluntad" (X, libro III), Montaigne vuelve al tema de los vicios y engaños, pero en torno a su práctica profesional. En ese ensayo, Montaigne recuerda cuando fue alcalde de Burdeos. Y ahí dice:

El alcalde y Montaigne siempre han sido dos, con una separación bien clara. No por ser abogado o financista debe desconocerse el engaño que hay en esas ocupaciones. Un hombre de bien no es culpable del vicio o estupidez de su oficio y en consecuencia no debe rechazar su ejercicio (907).

Montaigne resulta muy claro cuando afirma que hay una separación entre el hombre y su profesión; entre su honestidad como hombre

8 "Jenofonte, en su Vida de Ciro, muestra lo necesario que es engañar: considerando que la primera expedición que hizo Ciro contra el rey de Armenia estuvo llena de fraude [fraude] y fue con engaños [inganno], y no por la fuerza [forza], como logró ocupar ese reino, concluye, a la vista de tales acciones, que un príncipe que quiera hacer grandes cosas necesita aprender a engañar" (Maquiavelo 2000 230-231). 
y el vicio que portan ciertas profesiones. Parece que un hombre que es honesto puede ser indiferente al ejercicio de su ocupación laboral. Hay cargos públicos que tienen una moralidad propia y exigen cierta plasticidad en el ejercicio de los vicios, y pueden convivir con la honestidad como persona privada.

\section{Conclusiones}

A lo largo de este artículo buscamos indagar en las huellas de Maquiavelo que habitan en los Ensayos de Montaigne. Pero, para realizar ello, primero debimos analizar las evidencias explícitas que dieron cuenta de que Montaigne leyó al italiano. Como mencionamos en la introducción, este tópico fue abordado por la literatura especializada, ya para afirmar los puntos de contacto entre ambos autores o para decir todo lo contrario. Una vez sistematizada dicha evidencia, nos dirigimos hacia la presencia de Maquiavelo, pero desde un registro más sutil. Por más que en los ensayos "Sobre lo honesto y lo útil", "De la vanidad", "Si el jefe de una Plaza asediada debe salir a parlamentar" y "El peligroso momento de parlamentar" no hay referencia explícita a Maquiavelo, pudimos ver una problematización muy afín al autor italiano acerca de los dilemas de la vida política, sus vínculos con el engaño, la astucia y la dificultad de distinguir de modo taxativo entre lo bueno y lo malo. En este sentido, parece que hay un maquiavelismo que habita en Montaigne, que es aquel que reconoce la moralidad trágica que se pone en juego para quien quiera dedicarse a la política.

Si en la literatura especializada se ha observado una recepción del pensamiento de Maquiavelo en el de Montaigne, a través del trabajo de los rastros más sutiles podemos atrevernos a responder a la siguiente pregunta: ¿qué ilumina la figura de Maquiavelo en el pensamiento de Montaigne? Más allá del reconocido escepticismo de éste, creemos que se puede encontrar un pensamiento político dentro del linaje que comunica a Maquiavelo con Weber. Como la política implica una disputa de valores, aquellos príncipes que solo se movilizan por principios muy puros y abstractos, sin tomar en cuenta los vaivenes de la coyuntura, deberían retirarse de la vida del palacio. Es decir, esos personajes no tienen el espíritu ni vocación para dedicarse a la política. En este sentido, el pensamiento político de raíz maquiave- 
liana que puede hallarse en Montaigne parece mostrar otra capa en la textualidad del francés, más allá de su escepticismo. Montaigne muestra lo trágico de quien quiera dedicarse a la política porque, en determinados momentos, hay que saber engañar, ejercer la crueldad o traicionar algunas convicciones más íntimas. Como esperamos que haya quedado evidenciado en el artículo, hay un hilo que conecta a Montaigne con Maquiavelo o, para decirlo en palabras de Ginzburg, hay huellas de Maquiavelo en la textualidad de Montaigne. En este sentido, el arquetipo Maquiavelo puede ser visto como un desafío ético para Montaigne. El italiano muestra la disyuntiva que afronta cualquier persona que busca dedicarse a la política: la de ser fiel a su moralidad privada o a una pública. Esta situación no le generó a Maquiavelo ninguna incomodidad. En los Ensayos de Montaigne, por el contrario, habita una constante incomodidad que puede ser vista como la misma tensión que existe entre Maquiavelo y sus detractores.

\section{Bibliografía}

Bausi, Francesco. Maquiavelo. València: PUV Universitat de València, 2015.

Borghi, Guiliano. La politica e la tentazione tragica: la "modernità" in Machiavelli, Montaigne e Gracian. Milan: Franco Angeli, 1991.

Burke, Peter. Montaigne. Madrid: Alianza, 1985.

Desan, Philippe. The Oxford handbook of montaigne. Oxford University Press, 2016.

Fournel, Jean-Louis y Zancarini, Jean-Claude. Machiavel. Une vie en guerres. Paris: Passés Composés, 2020.

Ginzburg, Carlo. El hilo y las huellas. Lo verdadero, lo falso, lo ficticio. Buenos Aires: Argentina, 2010.

Grady, Hugh. "Afterword: Montaigne and Shakespeare in Changing Cultural Paradigms", Special section, Shakespeare and Montaigne revisited 6 (2006): 170-184.

Grady, Hugh. Shakespeare, Machiavelli and Montaigne: Power and Subjectivity from Richard II to Hamlet. Oxford: Oxford University Press, 2002.

Lefort, Claude. Le travail de l'oeuvre Machivel. Paris: Gallimard, 1986.

Lefort, Claude. Maquiavelo y lo político. Madrid: Trotta, 2010. 
Machiavelli, Bernardo. Libro di ricordi. Roma: storia e letteratura casa editrice, 2007.

Machiavelli, Niccolò. Tutte Le Opere. (al cuidado de Mario Martelli). Firenze: Sansoni, 1971.

Maquiavelo, Nicolás. Discursos sobre la primera década de Tito Livio. Madrid: Alianza. 2000.

Maquiavelo, Nicolás. El príncipe. Buenos Aires: Colihue, 2012.

Maquiavelo, Nicolás. Epistolario 1512-1527. México D.F.: FCE, 2013.

Montaigne, Michel de. Les Essais. Paris: Gallimard, 2009.

Montaigne, Michel de. Ensayos. Madrid: Losada, 2011.

Nicolai, Alexander. "Le 'machiavélisme' de Montaigne", Bulletin de la Société des amis de Montaigne 4 (1957): 11-21.

Panichi, Nicola. "Au-delà de la vertu 'innocente': Montaigne et les théoriciens de la raison d'état", Montaigne Politique. Ed. Phillippe Desan. Paris: Honore Champion, 2006.

Plutarco. Vidas Paralelas, Madrid: Gredos, 2009.

Rodríguez Rial, Gabriela. "Miedos políticos. Emociones, sentidos y efectos en tres momentos de la teoría política", Anacronismo e irrupción 10/19 (2020): 120-148.

Sanders, Sylvia G. "Montaigne et les idées politiques", Bulletin de la Société des Amis de Montaigne (1976): 18-19.

Sasso, Gennaro. Niccolò Machiavelli, storia del suo pensiero politico. Napolés: Istituto Italiano per gli Studi Storici, 1958.

Schaeffer, David Lewis. The Political Philosophy of Montaigne, Ithaca: Cornell UP, 1990.

Shklar, Judith. "Putting cruelty first", Daedalus (1982): 17-27.

Torres, Sebastián. Vida y tiempo de la república: contingencia y conflicto político en Maquiavelo. Los Polvorines: Universidad Nacional de General Sarmiento, 2013.

Villey, Pierre. Les sources et l'evolution des Essais de Montaigne. New York: Hachette, 1969.

Viroli, Maurizio. Il sorriso di Niccolò: storia di Machiavelli. Gius. BariRoma: Laterza \& Figli Spa, 2016.

Vivanti, Corrado. Los tiempos de la política. Buenos Aires: Paidós, 2013. Weber, Max. El político y el científico. Madrid: Alianza, 2009. 
Whitfield, John H. "Machiavelli Guicciardini Montaigne". Italian Studies 28/1 (1973): 31-47.

Zaharia, Oana-Alis. "Michel de Montaigne's Response to Machiavelli's Il Principe". East-West Cultural Passage 2 (2014): 7-28. 